\title{
Sleep disorders and relationship with comorbid anxiety and depression in carpal tunnel syndrome
}

\author{
Şükran Çevik Yurtoğulları1, Meral Seferoğlu ${ }^{2}$
}

${ }^{1}$ Department of Neurology, University of Health Sciences, Ankara Gaziler Physical Therapy and Rehabilitation Training and Research Hospital, Ankara, Turkey

${ }^{2}$ Department of Neurology, University of Health Sciences, Bursa Yuksek Ihtisas Training and Research Hospital, Bursa, Turkey

\begin{abstract}
Objectives: In this study, it was aimed to assess relationship of disease severity with sleep quality, depression and anxiety in patients with carpal tunnel syndrome (CTS) and to compare findings with healthy controls.

Methods: The study included 35 patients diagnosed as CTS and 20 healthy individuals. In CTS patients, symptom severity and functional disorders were assessed using Boston Carpal Tunnel Questionnaire (BTCQ). The sleep quality was assessed using Pittsburg Sleep Quality Index (PSQI) in CTS patients and healthy controls. The Beck Anxiety Inventory (BAI) and Beck Depression Inventory (BDI) were used to evaluate depression and anxiety accompanying to CTS and sleep disorder.
\end{abstract}

Results: In the assessment of general sleep quality, it was found that PSQI scores were significantly higher in CTS group when compared to healthy controls $(p<0.0001)$. Again, the BDI and BAI scores were also significantly higher in CTS group than control group ( $p<0.0001$ and $p<0.003$, respectively). There was a strong, positive correlation between BTCQ symptom severity scale (SSS) and PSQI ( $\mathrm{r}=0.774 ; p<0.0001)$. A significant, positive correlation was observed between Boston SSS and BDI scores $(\mathrm{r}=0.666 ; p<0.001)$. When assessed correlation between anxiety scores and Boston SSS and functional state scale (FSS), it was found that anxiety was increased by increasing severity of CTS, indicating a positive, moderate correlation ( $\mathrm{r}$ $=0.469, p<0.0001$ and $\mathrm{r}=0.464, p<0.0001)$.

Conclusions: The pain in patients with CTS can impair sleep quality, which, in turn, may increase risk for depression and anxiety. Thus, comorbid psychiatric symptoms and signs should be considered in the treatment of patients with CTS.

Keywords: Carpal tunnel syndrome, depression, anxiety, sleep disorder

$\mathrm{T}$ he carpal tunnel syndrome (CTS) is the most commonly seen entrapment neuropathy which results from compression of median nerve at level of wrist as it travels through carpal tunnel [1,2]. Paresthesia at dermatome of median nerve is typical in CTS. It is often seen in middle-aged women and its prevalence confirmed by clinical examination and elec- troneuromyography (ENMG) is $2.7 \%$ in general population. It is seen that pain and paresthesia (numbness, tingling) are classically enhanced at night time in $80 \%$ of patients and that these complaints are relieved by repositioning or shaking hands [3-5].

Although the diagnosis is supported by Tinel's test and Phalen's test, the definitive diagnosis is made using 
electrophysiological methods [6-8]. Since CTS symptoms are aggravated during night, it often causes sleep problems. Patients generally awake due to pain and paresthesia and attempt to relieve pain by shaking hands.

Sleep disorders can cause complaints such as concentration difficulty, mood disorder and increased pain, evolving to an important problem that negatively affects daily life of individual. The relationship between diseases and sleep has been investigated in many studies and it was shown that disorders characterized by pain affect sleep quality $[9,10]$.

In this study, it was aimed to compare depression, anxiety and sleep quality in patients diagnosed as CTS using ENMG with healthy controls and to identify severity of nerve injury on ENMG and depression, anxiety and sleep quality.

\section{METHODS}

\section{Study Population}

The study included 35 patients (aged 18-50 years) who presented to neurology outpatient clinic of Bursa Yuksek Ihtisas Training and Research Hospital and diagnosed as CTS with clinical findings and ENMG results according to American Association of Electrodiagnostic Medicine (AANEM) criteria between 2018 and December, 2019. In addition, 20 healthy controls were included to the study.

American Academy of Neurology criteria were used [11]. These criteria include: 1) Pain and paresthesia in the symptomatic hand at nights; 2) Sensational complaints during flexion and extension movements of wrist; 3) Pain and paresthesia in the morning; 4) Phalen's test positivity, 5) Sensation loss in median nerve innervation area; 6) Atrophy and weakness in median nerve innervated muscles. The patient was accepted to have CTS in the presence of at least one criterion.

The patients with systemic disease, B12 deficiency, cervical radiculopathy or rheumatoid disease, those with history of hand-wrist trauma or surgery, and those underwent corticosteroid injection to carpal tunnel area within prior 6 months were excluded. The study was approved by Ethics Committee of Bursa Yuksek Ihtisas Training and Research Hospital (approval\#: 13.02.3030-E1-20-155). All patients and con- trols gave written informed consent. In all patients included, detailed history was taken and physical and neurological examinations were performed.

\section{Electroneurophysiological Assessment}

All electroneurophysiological evaluations were performed by a single researcher and ENMG results were recorded. CTS staging was performed using Nihon Kohden Neuropack-S1 electromyography system (Tokyo, Japan) according to AANEM criteria [12].

Both hands were evaluated in all patients. Based on electroneurophysiological assessment, the patients were classified as follows:

Mild CTS: Prolonged distal sensory nerve conduction velocity and/or sensory nerve action potential amplitude below normal in median nerve.

Moderate CTS: Prolonged distal motor nerve action potential latency in median nerve in addition to above. Severe CTS: Lack of sensory nerve action potential and decreased amplitude or delayed latency of motor response.

\section{Boston Carpal Tunnel Questionnaire}

The Boston Carpal Tunnel Questionnaire (BTCQ) was used to assess symptom severity and functional disorders in the patients. The BTCQ was used to assess symptoms inn CTS patients, which includes 11 items and maximum score of 55 points. The BTCQ Turkish validity and reliability were proven [13]. There are two sub-domains in the questionnaire. The symptom severity scale includes 11 items rated by 5 points scale. Mean score was calculated by dividing total score into number of questions (mean score: 1-5 points). The functional status scale included 8 items rated by 5-points scale. Again, mean score was calculated by dividing total score into number of questions $(n=8)$. In both scale, maximum score was 5 . Higher scores indicate higher severity of symptoms and disability.

\section{Pittsburgh Sleep Quality Index}

The sleep quality was assessed using Pittsburgh Sleep Quality Index (PSQI) in CTS patients and controls. The PSQI provides a quantitative measure of sleep quality which differentiates good and poor sleep. The Turkish validity and reliability were studied by Agargun et al. [15] in 1996. It includes 24 items ad 7 
sub-domains: subjective sleep quality, sleep latency, sleep duration, habitual sleep efficiency, sleep disturbances, use of sleep medication, and daytime dysfunction. Each item was rated by 0-3 points scale. Total score of 7 sub-domains provides PSQI score (range: 0-21). Higher total PSQI score indicates poorer sleep quality. PSQI score $\geq 5$ indicates poor sleep quality [16].

\section{Beck Depression Inventory}

The Beck Depression Inventory (BDI) was developed to assess depression by Beck et al. [17]. The BDI aims to measure depressive measures and higher total scores indicate severity of depression level. It included 21 self-rated items and maximum total point is 63 . The Turkish validity and reliability were proven, and cutoff point was identified as 17 . In our study, 0-9 points indicates minimal depression, $10-16$ points mild depression, 17-29 points moderate depression and 30-63 points severe depression [18].

\section{Beck Anxiety Inventory}

The Beck Anxiety Inventory (BAI) was developed to anxiety symptoms by Beck et al. [19] and Turkish validity and reliability study was performed by Ulusoy et al. [20]. It is a self-rated questionnaire. It is used to determine frequency of anxiety symptoms experienced. There are 4 choices in 21 items. Each item is rated by $0-3$ points. Higher scores indicate severity of anxiety.

\section{Statistical Analysis}

The statistical analyses were performed using SPSS (Statistical Package for Social Sciences) for Windows version 20. The normal distribution was assessed using Shapiro-Wilk test. For continuous variables, descriptive statistics are presented as mean, standard deviation, minimum and maximum. For data with skewed distribution, Mann Whitney U test was used to compare continuous variables while Chisquare test was used to compare discrete variables. Coefficient of correlation was used to assess relationships between data with skewed variables or ordinal variables and statistical significant was calculated using Spearman's test. A $p$ value $<0.05$ was considered as statistically significant.

\section{RESULTS}

In our study, mean age was found as $46.1 \pm 11.4$ years in the CTS group and $40.6 \pm 10.5$ years in the control group. There was no significant difference in age between groups $(p=0.073)$. There were 27 women $(77.1 \%)$ and 8 men $(22.9 \%)$ in the CTS group while 17 women $(85.0 \%)$ and 3 men $(15.0 \%)$ in the control group (Table 1).

Mean CTS severity was calculated as $29.71 \pm 6.84$

Table 1. Demographic and clinical characteristics

\begin{tabular}{lccc}
\hline & $\begin{array}{c}\text { Total } \\
(\mathbf{n}=\mathbf{5 5})\end{array}$ & $\begin{array}{c}\text { CTS group } \\
(\mathbf{n = 3 5})\end{array}$ & $\begin{array}{c}\text { Control Group } \\
(\mathbf{n}=\mathbf{2 0})\end{array}$ \\
\hline Age (years) & $48.0 \pm 14.5$ & $46.1 \pm 11.4$ & $40.6 \pm 10.5$ \\
Gender, n (\%) & $44(80.0)$ & $27(77.1)$ & $17(85.0)$ \\
Female & $11(20.0)$ & $8(22.9)$ & $3(15.0)$ \\
Male & & & $4(20.0)$ \\
Education, $\mathbf{n}(\%)$ & $14(25.5)$ & $10(28.6)$ & $7(35.0)$ \\
Primary School & $17(30.9)$ & $10(28.6)$ & $9(45.9)$ \\
High School & $24(43.6)$ & $15(42.9)$ & $18(90.0)$ \\
University & & $31(88.6)$ & $2(10.0)$ \\
\hline Dominant side, $\mathbf{n}(\%)$ & $49(89.1)$ & $4(11.4)$ & \\
Right & $6(10.9)$ & & \\
Left & & & \\
\hline
\end{tabular}

Continuous data are presented as mean \pm standard deviation whereas discrete data are presented as frequency (\%). CTS

$=$ Carpal tunnel syndrome 
for Boston SSS whereas $17.60 \pm 7.62$ for Boston FSS. According to electrodiagnostic evaluation, 8 patients diagnosed as severe CTS while 16 patient as moderate CTS and 11 patients as mild CTS. In the CTS group, mean symptom duration was $13.09 \pm 10.8$ months. There was unilateral involvement in 16 patients $(45.7 \%)$ whereas bilateral in 19 patients $(54.3 \%)$. In patients with CTS, most common symptom was numbness detected in 14 patients $(40.0 \%)$ while pricking-tingling in one patient $(2.9 \%)$ (Table 2).

In the assessment of sleep quality, PSQI scores were found to be significantly poorer in patients with CTS compared to controls $(p<0.0001)$. Again, BDI and BAI scores were also significantly higher in CTS patients compared to controls $(p<0.001$ and $p<$ 0.003 , respectively) (Table 3 ).

There was a significant strong, positive correlation between Boston SSS and PSQI ( $\mathrm{r}=0.774 ; p<$ 0.0001). In addition, there was a significant strong, positive correlation between Boston FSS and PSQI ( $\mathrm{r}$ $=0.666 ; p<0.0001)$. It was found that there was significant, moderate, positive correlation between

Table 2. Comorbid symptom characteristics and disease severity in CTS patients

CTS Group

$(\mathbf{n}=35)$

\begin{tabular}{lc}
\hline Hand involved, $\mathbf{n}(\%)$ & $11(31.4)$ \\
Right & $5(14.3)$ \\
\hline Left & $19(54.3)$ \\
Bilateral & \\
Comorbid symptom, n (\%) & $3(8.6)$ \\
Pain & $14(40.0)$ \\
\hline Numbness & $2(5.7)$ \\
Burning sensation & $1(2.9)$ \\
\hline Pricking, tingling & $9(25.7)$ \\
Cramp & $4(11.4)$ \\
Pain + Numbness + Cramp & \\
EMG, n (\%) & $11(31.4)$ \\
Mild CTS & $16(45.7)$ \\
Moderate CTS & $8(22.9)$ \\
\hline Severe CTS & \\
\hline
\end{tabular}

Data are shown as frequency $(\%)$. CTS $=$ Carpal tunnel syndrome, $\mathrm{EMG}=$ Electomyography
Boston SSS and depression scores $(\mathrm{r}=0.514 ; p<$ $0.0001)$. When assessing correlation between anxiety scores and Boston SSS and FSS scores, it was found that anxiety was increased by enhancing CTS severity, indicating a significant, moderate, positive correlation $(\mathrm{r}=0.469, p<0.0001 ; \mathrm{r}=0.464, p<0.0001)$. The numbness was the most common symptom in CTS patients. Mean PSQI score was $13.7 \pm 4.02$ in CTS patients with numbness whereas $16.6 \pm 2.6$ in CTS patients without numbness. A significant difference was fund in PSQI scores between CTS patients with or without numbness $(p<0.045)$ (Table 4$)$.

\section{DISCUSSION}

Our results demonstrate that sleep quality is significantly impaired in patients with CTS. In our study, we found that CTS symptom severity significantly affected sleep quality and that there was a significant correlation between symptom severity and scores of depression and anxiety as well.

In the CTS, most important feature is pain and paresthesia which awake patient from sleep. To relieve these symptoms, the patients are awakening at night and shake or flail their hands which are distinctive for CTS [21]. In previous studies, it was shown that sleep was disturbed more commonly in CTS patients compared to healthy individuals and that paresthesia is the major factor for disturbed sleep [22, 23].

In CTS, the increased pain at night triggers sleep disturbance in the patient, affecting sleep quality. Impaired sleep quality has direct effects on daily living activities and emotional status [24, 25]. Thus, quality of life is affected by both pain itself and resultant impairments in sleep quality and emotional status in the patients [26]. In addition, it was found that sleep quality is further impaired by increasing CTS severity in our study, as similar to the study by Geoghegan et al. [27].

In a similar study using Brief Pain Inventory to evaluate pain, Nicholson and Verma reported that severity of pain was correlated to sleep disturbance [28]. Thus, it is important to question pain upon presentation in these patients. It is also important to determine severity of pain and treat pain in CTS patients.

In previous studies, it was found that depression and anxiety prevalence were higher in CTS patients 
Table 3. Comparison of groups regarding Pittsburgh sleep quality index total score, depression and anxiety

\begin{tabular}{lccc}
\hline & $\begin{array}{c}\text { CTS } \\
(\mathbf{n = 3 5})\end{array}$ & $\begin{array}{c}\text { Control } \\
(\mathbf{n = 2 0 )}\end{array}$ & $\boldsymbol{p}$ value \\
\hline Total Pittsburgh score & $16.0 \pm 3.20$ & $10.4 \pm 2.06$ & $<\mathbf{0 . 0 0 0 1}$ \\
BDI score & $13.45 \pm 9.13$ & $4.45 \pm 2.75$ & $<\mathbf{0 . 0 0 0 1}$ \\
BAI score & $13.02 \pm 11.97$ & $4.90 \pm 4.12$ & $<\mathbf{0 . 0 0 3}$ \\
\hline
\end{tabular}

Data are shown as mean \pm standard deviation. BAI $=$ Beck anxiety inventory, BDI $=$ Beck depression inventory, CTS

$=$ Carpal tunnel syndrome

Table 4. Correlation of Boston SSS and FSS scores with PSQI, depression and anxiety scores

\begin{tabular}{lccc}
\hline & PSQI & Beck Depression & Beck Anxiety \\
\hline Boston SSS & $\mathrm{r}=0.774$ & $\mathrm{r}=0.666$ & $\mathrm{r}=0.469$ \\
& $\boldsymbol{p}<\mathbf{0 . 0 0 0 1}$ & $\boldsymbol{p}<\mathbf{0 . 0 0 0 1}$ & $\boldsymbol{p}<\mathbf{0 . 0 0 0 1}$ \\
Boston FSS & $\mathrm{r}=0.672$ & $\mathrm{r}=0.514$ & $\mathrm{r}=0.464$ \\
& $\boldsymbol{p}<\mathbf{0 . 0 0 0 1}$ & $\boldsymbol{p}<\mathbf{0 . 0 0 0 1}$ & $\boldsymbol{p}<\mathbf{0 . 0 0 0 1}$ \\
\hline
\end{tabular}

PSQI = Pittsburgh Sleep Quality Index, SSS = symptom severity scale, FSS = functional state scale

compared to general population $[29,30]$. In agreement with literature, anxiety and depression scores were found to be higher in patients with high CTS symptom severity score in our study. In another study, it was shown that there was a correlation between pain and anxiety levels regardless of pain severity [31]. It has been thought that impaired sleep quality and accompanying findings such as numbness, tingling, pain, muscle cramps and burning sensation predispose to anxiety. The finding that there was a positive correlation between impaired sleep quality by increasing sleep quality and scores of anxiety and depression in ENMG results also supports this concept. The previous studies showed that depression is most common psychiatric disorder accompanying to neuropathic pain. In addition, pain and depression may trigger each other. The pain predisposes to depression while resultant depression lowers pain threshold and pain tolerance [32]. It has been suggested that the likelihood for exaggerated symptoms and seeking behavior for medical attention and altered pain perception in the presence of comorbid psychiatric disorders such as depression and anxiety is higher and that these patient have less flexibility to cope these diseases [33-35].

In diseases such as CTS where pain and paresthesia is prominent, the management generally focuses on treatment of pain. In most instances, comorbid sleep disorders, depression and anxiety aren't taken into consideration. The treatment of comorbid psychiatric disorders using short and simple scales such as BDI or BAI will improve success of pain management and quality of life in the patient. Adopting a wider perception before onset of vicious cycle including pain, sleep and psychiatric complaints and chronic disease will improve success of clinician and allow selecting appropriate treatment in the patient.

\section{Limitations}

This study has some limitations including lack of structured psychiatric interview to determine whether patient has any psychiatric diagnosis, failure to use objective sleep assessment tools and relatively smaller sample size.

\section{Strengths}

The strengths of study include assessment of psychological and physical factors together and presence of healthy control group.

\section{CONCLUSION}

In conclusion, the risk for impaired sleep quality, depression and anxiety accompanying to pain is found 
to be higher in CTS patients compared to healthy individuals. There is ease to used scales to detected comorbid condition in the management of CTS patients. The use of such scales in routine practice will improve treatment success and quality of life in the patients. There is a need for further studies using objective sleep assessment techniques and more detailed psychiatric interviews.

\section{Authors' Contribution}

Study Conception: ŞÇY; Study Design: ŞÇY; Supervision: ŞÇY, MS; Funding: ŞÇY, MS; Materials: ŞÇY; Data Collection and/or Processing: ŞÇY; Statistical Analysis and/or Data Interpretation: ŞÇY, MS; Literature Review: ŞÇY, MS; Manuscript Preparation: ŞÇY and Critical Review: ŞÇY, MS.

\section{Conflict of interest}

The authors disclosed no conflict of interest during the preparation or publication of this manuscript.

\section{Financing}

The authors disclosed that they did not receive any grant during conduction or writing of this study.

\section{REFERENCES}

1. Keith AB, Jeffrey JB. Hand Disorders. In: DeLisa JA, Gans BM, Walsh NE (Editors): Physical Medicine and Rehabilitation, 4th ed. Philadelphia, 2005:pp 843-54.

2. Şenel K. El ve El Bileği Ağrısı. Beyazova M, Gokce-Kutsal Y (Editorler). Fiziksel Tip ve

Rehabilitasyon. Ankara: Güneş Kitabevi, 2000, s.1455-64.

3. Graham B, Regehr G, Naglie G, Wright JG. Development and validation of diagnostic criteria for carpal tunnel syndrome. J Hand Surg Am 2006;31:919-24.

4. Wainner RS, Fritz JM, Irrgang JJ, Delitto A, Allison S, Boninger ML. Development of a clinical prediction rule for the diagnosis of carpal tunnel syndrome. Arch Phys Med Rehabil 2005;86:609-18.

5. Katz JN, Larson MG, Sabra A, Krarup C, Stirrat CR, Sethi R, et al. The carpal tunnel syndrome: diagnostic utility of the history and physical examination findings. Ann Intern Med 1990;112:321-7.

6. Gomes I, Becker J, Ehlers JA, Nora DB. Prediction of the neurophysiological diagnosis of carpal tunnel syndrome from the demographic and clinical data. Clin Neurophysiol 2006;117:964-71.

7. Katz JN, Larson MG, Sabra A, Krarup C, Stirrat CR, Sethi R, et al. The carpal tunnel syndrome: diagnostic utility of the history and physical examination findings. Ann Intern Med 1990;112:321-7.

8. Nora DB, Becker J, Ehlers JA, Gomes I. What symptoms are truly caused by median nerve compression in carpal tunnel syndrome? Clin Neurophysiol 2005;116:275-83.

9. Bigatti SM, Hernandez AM, Cronan TA, Rand KL. Sleep disturbances in fibromyalgia syndrome: relationship to pain and depression. Arthritis Rheum 2008;59:961-7.

10. Marty M, Rozenberg S, Duplan B, Thomas P, Duguesnoy B, Allaert F, Section Rachis de la Societe Francaise de Rhumatologie. Quality of sleep in patients with chronic low back pain: a case-control study. Eur Spine J 2008;17:839-44.

11. Jablecki CK, Andary MT, Floeter MK, Miller RG, Quartly CA, Vennix MJ, et al. Practice parameter: electrodiagnostic studies in carpal tunnel syndrome. Report of the American Association of Electrodiagnostic Medicine, American Academy of Neurology, and the American Academy of Physical Medicine andRehabilitation. Neurology 2002;58:1589-92.

12. Stevens JC. AAEM minimonograph 26: The electrodiagnosis of carpal tunnel syndrome. American Association of Electrodiagnostic Medicine. Muscle Nerve 1997;20:1477-86.

13. Sezgin M, Incel NA, Serhan S, Camdeviren H, As I, Erdogan C. Assessment of symptom severity and functional status in patients with carpal tunnel syndrome: reliability and functionality of the Turkish version of the BostonQuestionnaire. Disabil Rehabil 2006;28:1281-5.

14. Heybeli N, Özerdemoglu RA, Aksoy OG, Mumcu EF. [Functional and symptomatic scoring used for the assessment of outcome in carpal tunnel release]. Acta Orthop Traumatol Turc 2001;35:147-51. [Article in Turkish]

15. Ağargun MY, Kara H, Anlar O. [The Validity and Reliability of the Pittsburgh Sleep Quality Index]. Turk Psikiyatri Dergisi 1996;7(2). [Article in Turkish]

16. Buysse DJ, Reynolds CF 3rd, Monk TH, Berman SR, Kupfer DJ. The Pittsburgh Sleep Quality Index: a new instrument for psychiatric practice and research. Psychiatry Res 1989;28:193213.

17. Beck AT. An inventory for measuring depression. Arch Gen Psychiatry 1961;4:561-571.20.

18. Hisli N. Beck depresyon envanterinin üniversite öğrencileri için geçerliği, güvenirliği. Türk Psikoloji Dergisi 1988;6:3-13.

19. Beck AT, Epstein N, Brown G, Steer RA. An inventory for measuring clinical anxiety: psychometric properties. J Consult Clin Psychol 1988;56:893-7.

20. Ulusoy M. Beck Anksiyete Envanteri: Geçerlik ve güvenirlik çalışması. Yayınlanmamış uzmanlık tezi. Bakırköy Ruh ve Sinir Hastalıkları Hastanesi, İstanbul. 1993.

21. Ertekin C. Santral ve Periferik EMG Anatomi-FizyolojiKlinik. Izmir: Meta Basim Matbacilik Hizmetleri, 2006:403-27. 22. Patel JN, McCabe SJ, Myers J. Characteristics of sleep disturbance in patients with carpal tunnel syndrome. Hand (N Y) 2012 7:55-8.

23. Lehtinen I, Kirjavainen T, Hurme M, Lauerma H, Martikainen K, Raulaha E. Sleep related disorders in carpal tunnel syndrome. Acta Neurol Scand 1996;93:360-5.

24. Annagür BB, Uguz F, Apiliogullari S, Kara I, Gunduz S. Psychiatric disorders and association with quality of sleep and quality 
of life in patients with chronic pain: A SCID-Based Study. Pain Med 2014;15:772-8.

25. Alsaadi SM, McAuley JH, Hush JM, Bartlett DJ, McKeough ZM, Grunstein RR et al. Assessing sleep disturbance in low back pain: the validity of portable instruments. PLoS One 2014;9:e95824.

26. Stewart WFRJ, Chee E, Brandenberg N. Work related costs of diabetic neuropathic (DPN) Pain in the US: results from the american productivity audit. In: 24th Annual Scientific Meeting of the American Pain Society, Boston, Mass. 2014.

27. Geoghegan JM, Clark DI, Bainbridge LC, Smith C, Hubbard R. Risk factors in carpal tunnel syndrome. J Hand Surg $\mathrm{Br}$ 2004;29:315-20.

28. Nicholson B, Verma S. Comorbidities in chronic neuropathic pain. Pain Med 2004;5(Suppl s1):S9-27.

29. Beleckas CM, Wright M, Prather H, Chamberlain A, Guattery J, Calfee RP. Relative prevalence of anxiety and depression in patients with upper extremity conditions. J Hand Surg Am 2018;43:571.e1-571.e8.)

30. Moghadam-Ahmadi A, Bidaki R, Sarhadi TS, Vakilian A,
Razavi AS. Prevalence of depression and anxiety in patients with carpal tunnel syndrome, Rafsanjan, Iran 2014. J Mazandaran Univ Med Sci 2017;27:64-73.

31. McCallum LM, Damms NA, Sarrigiannis PG, Zis P. Anxiety and depression in patients with suspected carpal tunnel syndrome - A case controlled study. Brain Behav 2019;9:e01342.

32. Radat F, Margot-Duclot A, Attal N. Psychiatric co-morbidities in patients with chronic peripheral neuropathic pain: a multicentre cohort study. Eur J Pain 2013;17:154-7.

33. Cameron LD, Leventhal H, Love RR. Trait anxiety, symptom perceptions, and illness-related responses among women with breast cancer in remission during a tamoxifen clinical trial. Health Psychol 1998;7:459-69.

34. Hazard RG, Bendix A, Fenwick JW. Disability exaggeration as a predictor of functional restoration outcomes for patients with chronic low-back pain. Spine (Phila Pa 1976) 1991;16:1062-7. 35 . Howren MB, Suls J. The symptom perception hypothesis revised: depression and anxiety play different roles in concurrent and retrospective physical symptom reporting. J Pers Soc Psychol 2011;100:182-95. 